\title{
A test of the odor hypothesis using Mongolian gerbils and a random trials procedure
}

JEFF S. TOPPING and JOHN M. COLE, University of Portland, Portland, Oreg. 97203

In a test of the odor hypothesis, two groups of Mongolian gerbils were given straight-alley trials, with a 50\% schectule of reinforcement. For the experimental group, all $S$ s received the same goal treatment, either reinforcement $(R)$ or nonreinforcement $(N)$, on a given trial. For the control group, $S$ s were given either $R$ or $N$ treatments randomly within a given trial. To eliminate intertrial carry-over of odor cues, the alley was cleaned with a damp sponge each time all Ss in the experimental or control group completed a trial. With this procedure, odor cues were informative only for the experimental group. Results substantiated the odor hypothesis in that experimental Ss ran relatively slower in the goal section on $N$ than on $R$ trials, whereas control Ss did not. When the wipe-out procedure was discontinued, thereby confusing odor cues for the experimental group, differential goal latencies on $R$ and $N$ trials disappeared.

The odor hypothesis (Ludvigson \& Sytsma, 1967) suggests that rats in the traditional straight-alley runway are capable of exuding quantitatively and/or qualitatively different odors in the goalbox, depending on whether the trial was reinforced (R) or nonreinforced $(N)$. These odors persist to succeeding trials and have been shown to serve as potential discriminative stimuli for succeeding Ss. More specifically, Ludvigson \& Sytsma (1967) have shown that rats with differential odor cues available exhibit relatively faster goal speeds on $\mathbf{R}$ trials than on $\mathrm{N}$ trials; $\mathrm{Ss}$ without these cues available do not show this difference. More recently, Ludvigson (1969) replicated these findings and in addition made the following discoveries: (a) using rats as $\mathrm{Ss}$, the differences in $\mathbf{R}$ vs $\mathbf{N}$ goal speeds partially depends on using a trial sequence which is constant from day to day, and (b) Ss given odor cues of two preceding Ss, Sn -1 receiving the opposite and $\mathrm{Sn}-2$ the same reinforcement event, do not exhibit the $R$ vs $N$ goal-speed differences. In addition, McHose \& Ludvigson (1966) have shown that control Ss given the same reinforcement conditions in two distinctly different alleys will tend to start faster in the alley used for the more favorable of two incentives for the preceding experimental Ss.
The present study attempted to test the generality of the odor hypothesis by (a) using Mongolian gerbils, Meriones unguiculatus, as Ss rather than rats; (b) implementing a daily sequence of $\mathbf{R}$ and $N$ trials which was determined randomly each day; and (c) testing the extent to which the differential goal speed effect is dependent on the previously used technique of wiping out the alley prior to each trial, thereby eliminating in ter trial cues.

\section{METHOD}

The Ss were 14 Mongolian gerbils, six males and eight females, ranging in age from 70 to 119 days at the start of the experiment.

The apparatus was a grey alley, $76 \times 4 \times 9$ in., with $14 \frac{1}{2}$-in. start, $471 / 2$-in. nu, and 14-in. goal sections, separated by wooden guillotine doors. A 2 -in. glass caster wrapped with black tape was employed as the food cup and was located on the floor against the end wall of the goal section. Quarter-inch wire mesh covered the top of the alley. Standard interval timers measured start(first 15 in.), run (next 46 in.), and goal (next 10 in.) latencies on each trial.

One week prior to acquisition, Ss were put on a food-deprivation schedule and

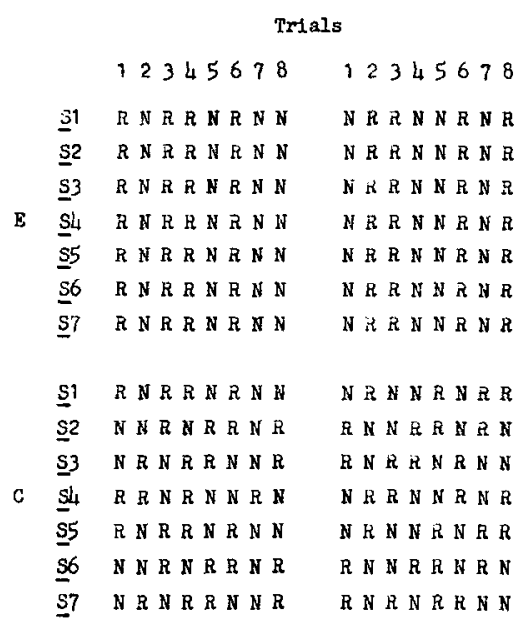

Table 1

Typical Two-Day Schedules of Reinforcement (R) and Non-Reinforcement (N) for Experimental (E) and Control (C) Groups reduced to $85 \%$ of their ad lib weights. These $85 \%$ weights were continually adjusted to control for normal weight increases due to maturation.

During the 5 days preceding acquisition, Ss were pretrained and habituated to the alley. On Days 1-2, individual $S s$ were given a 5-min exploration period in the alley with guillotine doors raised and the food cup empty. On Days 3-5, all Ss received four trials daily, $50 \%$ of which were reinforced according to a random schedule.

Following pretraining and habituation, Ss were split into two groups which were matched for sex and weight. During Phase 1 of acquisition, all $S s$ received eight trials daily, $50 \%$ reinforced, for 12 days. On each trial, Ss were placed in the start section, the guillotine door separating the start and run sections was raised, and Ss were allowed to run to the food cup. After Ss entered the goal section, the guillotine door separating the goal and run sections was lowered, and Ss were confined for approximately 20 sec. On reinforced trials, $S$ s received one medium-sized sunflower seed in the food cup; on nonreinforced trials, the cup was empty. Within each group, the Ss' order of running on each ordinally numbered trial was constant from day to day; also, a given group received all of its daily trials before the other group received its trials, the two groups being first on alternate days.

Experimental and control groups differed with respect to the within-trial sequence of reinforcement. For the experimental group, all $S$ s received the same goal event, either $R$ or $\mathrm{N}$, on a given trial. For the control group, Ss received different, randomly ordered goal events within each trial. Typical 2-day sequences are presented in Table 1. After all Ss in either group had completed a given trial, odor cues were eliminated by carefully cleaning out the entire alley with a damp sponge. In addition, any defecation, urination, or sunflower shells were removed between the running of any two Ss in an attempt to minimize any distracting stimuli. Although both groups received randomly ordered $\mathbf{R}$ and $\mathbf{N}$ trials each day, reinforcement conditions for experimental Ss were the same within trials, random across trials; reinforcement conditions for control Ss were random within and across each trial. With this procedure, Ss in the experimental group could conceivably pick up olfactory cues left in the goalbox by immediately preceding Ss. These cues could serve to inform these $S s$ as to whether he would or would not receive reinforcement on that trial before he actually looked in the food cup. If this is, in fact, what is happening, experimental Ss would be expected to run more slowly in the goal section on $\mathrm{N}$ trials relative to $\mathrm{R}$ trials. These differences would not be expected to occur 


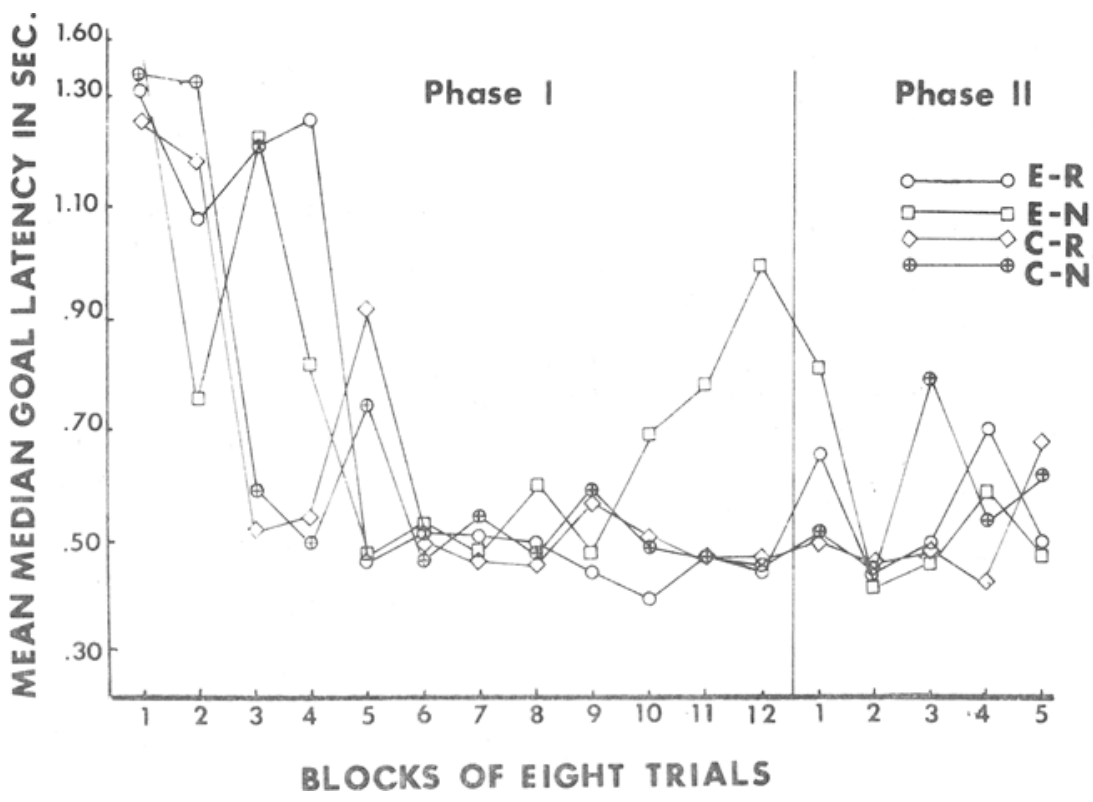

for the control Ss, since no reliable information as to $\mathrm{R}$ or $\mathrm{N}$ is conveyed.

During Phase 2, Ss were run for an additional 5 days, with the only procedural change being that the alley was never cleaned out. If persistent and effective differential odors were being produced in Phase 1, then the lack of cleaning should result in the alleviation of the patterning effect. That is, odor traces from both $R$ and $\mathrm{N}$ trials would be present on many trials and the Ss would not have any basis for differential responding. RESULTS

Figure 1 presents the mean median goal latencies during both phases of acquisition. Data for the first $S$ in each group was eliminated from this figure and from all succeeding statistical analyses. In addition, one other $S$ was eliminated from the experimental group since this $S$ had latencies which consistently deviated from latencies of all other Ss. Observation of Fig. 1 generally indicates that while both groups were initially equivalent on both $R$ and $N$ trials, goal latencies on $\mathbf{N}$ trials for the experimental group became reliably slower by the final acquisition days of Phase 1 .

A 2 (groups) by 2 (reinforcement events) by 4 (blocks of trials) repeated-measures ANOVA was performed on mean median goal latencies for Blocks 9-12 of Phase 1 . The main effect for reinforcement events $(R$ vs $\mathrm{N})$ was significant $(\mathrm{F}=12.81, \mathrm{df}=1 / 9$,

Mean median goal latencies of Phase 2 are also shown in Fig. 1. A 2 (groups) by 2 (reinforcement events) by 5 (blocks) repeated-measures ANOVA was performed on these data. No significant main effects or interactions were found. These results suggest that when the cleaning procedure is discontinued, thereby causing intertrial confusion of olfactory cues, the $R$ vs $N$ patterning for the experimental Ss is lost. show any patteming effect during either phase of the present study.
Fig. 1. Mean median goal latencies during Phases 1 and 2 for experimental $R$ (E-R), experimental $\mathbf{N}(\mathrm{E}-\mathrm{N})$, control $\mathbf{R}(\mathrm{C}-\mathrm{R})$, and control N (C-N) trials.

\section{DISCUSSION}

The present study tested the generality of the odor hypothesis (Ludvigson \& Sytsma, 1967) by varying the species of Ss, trial sequences, and alley cleaning procedures. Although previous studies dealing with the odor hypothesis have attempted to generalize their findings to the "traditional" partial reinforcement (PR) alley studies, the two situations differ in at least two important ways. Studies dealing with the odor hypothesis typically have used a constant daily pattern of trials (single or double alternation) and very stringent alley cleaning procedures to eliminate intertrial cues. On the other hand, more traditional PR studies have used random trial sequencies and infrequent, unsystematic and incomplete alley cleaning procedures.

In Phase 1 of the present study, the odor hypothesis was tested using a random trials sequence and stringent in tertrial elimination of odor cues. Results of this phase indicate that the patterned running found in previous tests of the odor hypothesis was also found under the present conditions. In Phase 2 of the present experiment, which very closely approximated the traditional $P R$ procedure using random trial sequences and no alley cleaning, the patterning effect was not found. Thus, the possibility that results of previous PR alley studies were confounded by responses to differential odor cues is not substantiated. The present experiment should be replicated with laboratory rats in order to more closely approximate the typical PR alley study.

\section{REFERENCES}

Start and run latency measures did not
LDVIGSON, H. W. Runway behavior of the rat as a function of intersubject reward contingencies and constancy of daily reward schedule. Psychonomic Science, 1969, 15, 41-43.

LUDVIGSON, H. W., \& SYTSMA, D. The sweet smell of success: Apparent double alternation in the rat. Psychonomic Science, . 1967, 9, 283-284.

McHOSE, J. H., \& LUDVIGSON, H. W. Differential conditioning with nondifferential reinforcement. Psychonomic Science, 1966, 6, 485-486. 